\title{
Classification of Sandstorms in Saudi Arabia
}

\author{
Ayisha A. Arishi \\ Jazan University, Jazan, KSA \\ Email: aiarishi@jazanu.edu.sa
}

How to cite this paper: Arishi, A.A. (2021) Classification of Sandstorms in Saudi Arabia. Atmospheric and Climate Sciences, 11, 177-193.

https://doi.org/10.4236/acs.2021.111012

Received: November 14, 2020

Accepted: January 23, 2021

Published: January 26, 2021

Copyright $\odot 2021$ by author(s) and Scientific Research Publishing Inc. This work is licensed under the Creative Commons Attribution International License (CC BY 4.0).

http://creativecommons.org/licenses/by/4.0/

\begin{abstract}
The aim of the study is to classify the Sandstorms according to year seasons as well as their spatial variation in Saudi Arabia. Factor analysis has been used for data collection. Three factors have been presented: the first factor related to Spring as a prime Season for Dust Sandstorms. Factor two shows that Samar months concern as ascend season for Sandstorms, while the Autumn Season comes as a third period for Dust Sandstorms. With regard to spatial variation, Al-Ahsa station came as the most closely related station in the spring season, followed by Hafr Elbatten, Jazan and Al-Jouf stations, while Jazan and Yenbo stations were the most connected stations in the summer season, Turaif is more closely related, to Fall season. By the end of the study several results and recommendations have been addressed.
\end{abstract}

\section{Keywords}

Sandstorms, Classification, Spatial Variation, Saudi Arabia

\section{Introduction}

Sandstorm is meteorological phenomenon in which the wind speed increases to reach between 54 and $63 \mathrm{~km} / \mathrm{h}$, the relative humidity drops to less than $70 \%$, and is loaded with dust and sand raised from topsoil, sand wedge, sand dune, where the winds raise the dust to high altitudes of thousand meters. The horizontal vision weakens to less than 1000 meters causing white-out [1]. Sand or dust storm formed as a high dust wall "approximately 3000 meters" wide and tens and hundreds of kilometers wide.

Sandstorms are considered one of the most important weather phenomena characterizing KSA. This phenomenon is affected by many factors that have contributed to the variation of spatial and temporal classification. Among the most prominent of these factors is the geographical location in the far south-west of the continent of Asia, the astronomical position between Longitude 16 and 32, and 
Latitude 34 and 56, which made most of the Kingdom's lands fall within desert areas whose precipitation rate does not exceed $50 \mathrm{~mm}$. Also, it is characterized by increased rates of wind speed, which is affected by the occurrence of atmospheric depressions, in addition to its proximity to I.T.C.Z. KSA is also characterized by the variation of the terrain in an area of 2.25 million $\mathrm{km}^{2}$.

The most distinctive features of the surface nature in the Kingdom of Saudi Arabia are the expansion of the sand cover area, which ignites about $34 \%$ of the total area. The sandy areas are represented in the Empty Quarter, Al-Nofuth and Al-Dahna desert, which extend in most regions of the Kingdom. This has led to a lack of vegetation cover and thus loosening of the soil and its lack of cohesion during the winds, which contributed to the increase in sandstorm activity and therefore caused lack of cohesion during the winds, which contributed to the increase in sandstorm activity. Sandstorms are also affected by many external weather factors, the most important of which are depressions and air currents resulting from atmospheric instability.

In view of the impact of sandstorms on various areas of development in KSA, and due to the lack of studies concerned with this aspect, this study has focused on classifying sandstorms in the Kingdom of Saudi Arabia in terms of time classification during the months of the year, as well as spatial classification in various monitoring stations Air in the Kingdom of Saudi Arabia, and highlighting the stations most affected by that phenomenon, according to the seasons of the year.

\section{Objectives of the Study}

The main objective of the study is to analyze the classification of the sandstorms in Saudi Arabia, and from this goal the following objectives emerge:

- Determine the seasons in which the most frequent sandstorms occur in the Kingdom of Saudi Arabia.

- Determine the seasons with least number of sandstorms occur in the Kingdom of Saudi Arabia.

- Highlight the spatial variation of sandstorms in the regions of Saudi Arabia in light of their temporal classification.

- Develop recommendations that will help in reducing the impact of sandstorms according to their geographical distribution.

\section{Data Sources}

This study relied on the following sources:

- The Statistical Yearbook, from 1989 to 2019, Ministry of Economy and Planning, Department of Statistics and Information, various issues [2].

- Data of the General Authority for Statistics from 1989 to 2019, which included 27 stations stated in Table 1, and Figure 1.

- Topographic and natural maps of the Kingdom of Saudi Arabia of various sizes, which were obtained by the Ministry of Municipal and Rural Affairs. 
Table 1. Meteorological stations in the study area.

\begin{tabular}{|c|c|c|c|c|c|c|c|c|c|c|}
\hline \multirow{2}{*}{ Number } & \multirow{2}{*}{ Station } & \multicolumn{2}{|c|}{ Station Symbol } & \multicolumn{3}{|c|}{ Longitude } & \multicolumn{3}{|c|}{ Latitude } & \multirow{2}{*}{$\begin{array}{c}\text { Height } \\
\text { METER }\end{array}$} \\
\hline & & ICAR & WMO & DEG & MIN & SEC & DEG & MIN & SEC & \\
\hline 1 & Turaif & OETR & 40,356 & 38 & 44 & $22 \mathrm{E}$ & 31 & 41 & $16 \mathrm{~N}$ & 852.44 \\
\hline 2 & Arar & OERR & 40,357 & 41 & 08 & $26 \mathrm{E}$ & 30 & 54 & $08 \mathrm{~N}$ & 548.88 \\
\hline 3 & Guriat & OEGT & 40,360 & 37 & 16 & $56 \mathrm{E}$ & 31 & 24 & $27 \mathrm{~N}$ & 503.90 \\
\hline 4 & Al-Jouf & OESK & 40,361 & 40 & 05 & $55 \mathrm{E}$ & 29 & 47 & $19 \mathrm{~N}$ & 668.74 \\
\hline 5 & Rafha & OERF & 40,362 & 43 & 29 & $49 \mathrm{E}$ & 29 & 37 & $17 \mathrm{~N}$ & 444.10 \\
\hline 6 & Gaisumah & OEBA & 40,373 & 46 & 07 & $49 \mathrm{E}$ & 28 & 19 & $08 \mathrm{~N}$ & 357.60 \\
\hline 7 & Tabuk & OETB & 40,375 & 36 & 36 & $25 \mathrm{E}$ & 28 & 22 & $35 \mathrm{~N}$ & 768.11 \\
\hline 8 & Hafr Elbatten & OEKK & 40,377 & 45 & 32 & $00 \mathrm{E}$ & 27 & 54 & $00 \mathrm{~N}$ & 413.0 \\
\hline 9 & Hail & OEHL & 40,394 & 41 & 41 & $28 \mathrm{E}$ & 27 & 26 & $04 \mathrm{~N}$ & 1001.52 \\
\hline 10 & Wejh & OEWJ & 40,400 & 36 & 28 & $37 \mathrm{E}$ & 26 & 12 & $19 \mathrm{~N}$ & 23.73 \\
\hline 11 & Qassim & OEGS & 40,405 & 43 & 46 & $03 \mathrm{E}$ & 26 & 18 & $28 \mathrm{~N}$ & 646.71 \\
\hline 12 & Dhahran & OEDR & 40,416 & 50 & 09 & $39 \mathrm{E}$ & 26 & 15 & $34 \mathrm{~N}$ & 16.77 \\
\hline 13 & Al-Ahsa & OEAH & 40,420 & 49 & 29 & $11 \mathrm{E}$ & 25 & 17 & $53 \mathrm{~N}$ & 178.17 \\
\hline 14 & Madinah & OEMA & 40,430 & 39 & 41 & $55 \mathrm{E}$ & 24 & 32 & $53 \mathrm{~N}$ & 625.60 \\
\hline 15 & Riyadh & OERY & 40,438 & 46 & 44 & $18 \mathrm{E}$ & 24 & 42 & $40 \mathrm{~N}$ & 619.63 \\
\hline 16 & Yenbo & OEYN & 40,439 & 38 & 03 & $50 \mathrm{E}$ & 24 & 08 & $24 \mathrm{~N}$ & 10.40 \\
\hline 17 & Jeddah & OEJN & 41,024 & 39 & 08 & $54 \mathrm{E}$ & 21 & 40 & $42 \mathrm{~N}$ & 3.58 \\
\hline 18 & Makkah & OEMK & 41,030 & 39 & 46 & $08 \mathrm{E}$ & 21 & 26 & $16 \mathrm{~N}$ & 240.35 \\
\hline 19 & Taif & OETF & 41,036 & 40 & 32 & $56 \mathrm{E}$ & 21 & 28 & $44 \mathrm{~N}$ & 1452.75 \\
\hline 20 & Al-Baha & OEBA & 41,055 & 41 & 38 & $35 \mathrm{E}$ & 20 & 17 & $41 \mathrm{~N}$ & 1651.88 \\
\hline 21 & Wadi Dawasir & OEWD & 41,061 & 44 & 40 & $49 \mathrm{E}$ & 20 & 26 & $30 \mathrm{~N}$ & 701.02 \\
\hline 22 & Bisha & OEBH & 41,084 & 42 & 37 & 09E & 19 & 59 & $28 \mathrm{~N}$ & 1161.97 \\
\hline 23 & Abha & OEAB & 41,112 & 42 & 39 & $39 \mathrm{E}$ & 18 & 13 & $59 \mathrm{~N}$ & 2093.35 \\
\hline 24 & Khamis Mushait & OEKM & 41,114 & 42 & 48 & $23 \mathrm{E}$ & 18 & 17 & $58 \mathrm{~N}$ & 2055.93 \\
\hline 25 & Najran & OENG & 41,128 & 44 & 24 & $49 \mathrm{E}$ & 17 & 36 & $41 \mathrm{~N}$ & 1212.33 \\
\hline 26 & Sharorah & OESH & 41,136 & 47 & 06 & $29 \mathrm{E}$ & 17 & 28 & $04 \mathrm{~N}$ & 724.65 \\
\hline 27 & Jazan & OEGN & 41,140 & 42 & 35 & $05 \mathrm{E}$ & 16 & 53 & $49 \mathrm{~N}$ & 7.24 \\
\hline
\end{tabular}

Source: General authority of meteorology and environmental protection, 2019 [2].

\section{Methodology}

This study relied on the Analytical method based on the deductive approach derived from the data obtained from 27 meteorological stations spread across the king dam's regions. The study mainly used Factor Analysis Method, by which sandstorms were classified according to the season of the year, as well as to their spatial distribution and variation in Saudi Arabia. 




Figure 1. Stations of the study area. Source: From the work of the researcher based on the ministry of meteorology and environmental protection, Kingdom of Saudi Arabia.

\section{Previous Studies}

There are many studies concerned with the issue of sandstorm in different regions, some of those studies will be referred to:

Al-Qalawi Study (1983) on climate and its impact on the environment in the Western Desert of Egypt [3], which showed its impact of sandstorm on the environment in the western desert of Egypt, as well as their direct effects on green spaces in oases, roads, human and animal health. The study also confirmed that the cause of such storms as activity of the pentathlon depressions in the spring, and the fast winds accompanying them, as well as high temperature and low humidity.

Safar (1985) reviewed the dust and sandstorm in Kuwait, where it focused on dust storms and confirmed the number of days of their occurrence [4]. The study also showed that each type of weather phenomenon differs in terms of its speed, including dust storms occurring if the wind speed reaches $18 \mathrm{knots}$, and in his study he was keen on the distribution of dust and dust storms geographically in Kuwait, as well as their number, reasons for their occurrence, and the most important methods through which such storms could be confronted.

Al-Kulibi (1990) dealt with the climate of the Arabian Gulf about dust and dust storms, and mentioned that they occur in the cold seasons extending from November to April, as a result of the high wind speed during the crossing of the active western depressions, or in the hot seasons from June to September due to 
the influence of the Arabian Gulf as a result of Indian seasonal depression [5]. He also indicated that the northern part of the Arabian Gulf is exposed to sandstorms more than its southern part. As for the seasonal variation, he mentioned that the summer season is exposed to sandstorms more than any other season, and dust storms tend to occur in the day more than at any other time, while they decrease in the early morning.

Taher study (1996) explained sand and dust storms and their impact on the soil of agricultural fields in Al-Ahsa-KSA and focused on highlighting their relationship [6], as it was concerned with determining the number of days of drifting and blowing sand and dust. It also aimed at showing the relationship between wind speed and various other specific weather elements such as air pressure, humidity and temperature, and analyzing the effect of this sand drift on the agricultural fields' soils.

Salim study (2000) reviewed storms and their dangers, especially tropical storms in terms of their origins [7], routes and geographical distribution. The study also reviewed khamsin winds and showed that they are hot winds, whose temperature rises sometimes to $45^{\circ}$ and is also dusty and very dry, and blows intermittently in the spring and its formation refer to the Mediterranean depressions. The study also explained that it has an impact on the environment, especially plants.

Tayyib and Jarar study (2002) about sand pollution. The two researchers dealt with both accumulated dust and suspended dust [8], and then clarified the most important dangers of dust to humans, animals, plants, and various environmental systems according to their size and different chemical nature, and the most important controlling standards highlighted air pollution with dust.

Salem study (2004) the researcher dealt with sand and dust storms and their impact on agriculture in the Jazan region [9]. The study aimed at finding out the causes of their occurrence, geographical distribution, in addition to their impact on some agricultural crops. This study concluded that storms have a direct and indirect effect on crops, especially vegetables such as tomatoes and fruit trees such as mangoes, bananas, papayas, and palms, especially in the western region where Tihama plain and the study recommended the continuation of climate research in the Jazan region.

Arishi study (2008): the researcher reviewed the effect of sand and dust storms and thunderstorms on the environmental development in the Jazan region [10]. It also showed that the most frequent seasons show the occurrence of sandstorms in the Jazan region that occur in summer season, as sand and dust storms increase compared to the winter season. The study concluded that there are many problems that face the population when sand and dust storms occur in the Jazan region, the most important of which is the difficulty of movement and walking on roads due to poor horizontal vision.

Al-Mutairi study (2015) entitled "Dust storms in the regions of Riyadh and Qassim, and the climatic factors affecting them" [11]. The study concluded that sandstorms in the city of Riyadh increase in the spring and summer and de- 
crease in Fall. Also, it reached a strong direct correlation between the frequency of dust and sandstorms and the group of patients with allergic chest disease, as well as between it and wind speed and finally recommended support for applied research in the field of climate.

Abd Al-Halim study, (2015) entitled "sandstorms and their impact on some agricultural crops in the western part of the Republic of Northern Sudan". The study results indicated that the high temperature and the decrease in atmospheric pressure helped in increasing the activity of sandstorms in western Sudan [12], and led to economic losses in agriculture represented by, in the diminishing productivity of acre. The study recommended using remote sensing technology in early detection of sandstorms.

Habib study (2016) entitled "Monitoring and analyzing violent sand storms in the Kingdom of Saudi Arabia using satellite images" [13]. The study found that the wind speed increases in the spring season in the north and center of the Kingdom, which helps in the occurrence of violent storms in these areas, as a result of the activity of exciting household load currents. The study also highlighted the presence of two types of storms in the Kingdom, the first is less severe storms that move to the Kingdom from Africa through the Red Sea, and the second violent storms originating from sandy areas in the Kingdom and affected by the atmospheric pressure areas over the Arabian Peninsula.

Al-Loula study (2017) entitled "sand storms and their impact on agricultural crops in the central region of the Kingdom of Saudi Arabia, from 2001 till 2016" [14]. The study reviewed natural and human factors affecting the occurrence of sandstorms in the middle of the Kingdom. The study concluded that sandstorms affect $56 \%$ of agricultural crops, and the effect increases during the winter compared to the summer and finally concluded with many recommendations.

From the analysis of previous studies with their various topics of locations, it can be mentioned that this study comes within the system of those studies, taking advantage of analysis of sandstorms. The method used and the results of those studies. However, his study is one of the applied climate studies that provides a clear analytical view on sandstorms in Saudi Arabia, based on one quantitative analysis such as the Factor Analysis Method, through which the sandstorm phenomenon in Saudi Arabia was classified accurately in accordance with time factor associated with months of year as well as spatial factor associated with the regions of the country.

\section{Data Analysis}

\subsection{Seasonal Classification of Sandstorm in Saudi Arabia}

The data of the monthly average frequency of sandstorms during the period from (1989-2019) were relied on in the classification of sandstorms in the Kingdom of Saudi Arabia. Such classification included a period of up to 30 years, in 27 stations of meteorological stations distributed in the various regions of the Kingdom of Saudi Arabia (see Appendix Table A1). The study data were ana- 
lyzed using the factor analysis method as follows:

1) Extracting KMO value in order to verify quality of data analysis in the selected monitoring stations, and to verify their suitability for the analysis, this requires that its value exceeds $(0.60)$. In the event that the value is less than this number, re-analysis is required. Table 2 shows that value as it reached (0.734), and the level of statistical significance (0.00) confirms the adequacy of the data used to achieve the results of the study.

2) Determining communalities values which refer to total contributions to the derivative factors representing one of global analysis outputs. The results of this analysis are evident in Table 3, and through it, the percentage of the contribution of each month of the year is clear, and the highest value recorded in the month of August, with a value of $(0.95 \%)$, that is what is equivalent to this percentage of basic information in this month has been interpreted in the three derived factors, followed by October at a rate of $(0.91 \%)$, and the same is the case in the rest of the other months for which the table indicates high contribution to the variance ratio.

Table 2. Checking the quality of the study data analysis.

\begin{tabular}{ccc}
\hline \multicolumn{2}{c}{ KMO and Bartlett's Test $^{\mathbf{a}}$} \\
\hline Kaiser-Meyer-Olkin Measure of Sampling Adequacy. & 0.734 \\
Bartlett's Test of Sphericity & Approx. Chi-Square & 333.210 \\
Sig. & 0.000 \\
\hline
\end{tabular}

Source: Factor analysis outcomes. a. Based on correlations.

Table 3. The values of communalities.

\begin{tabular}{cc}
\hline Component & Communalities \\
January & 0.723 \\
February & 0.905 \\
April & 0.892 \\
May & 0.847 \\
June & 0.759 \\
July & 0.868 \\
August & 0.823 \\
September & 0.958 \\
October & 0.877 \\
November & 0.911 \\
December & 0.763 \\
\hline
\end{tabular}

Source: Factor analysis outcomes. 
3) Analyzing the derivative factors and variance ratios for each factor depending on the "cut off point" which was determined on the basis of "Eigen Values" which exceed (1). According to Table 4 and Figure 2, it was clear that three main factors have been identified that exceed (1) integer. the first factor is the most important of these factors because it included large Initial Eigenvalues amounting 5561 and 45,510\% of variance, and Cumulative \% in the main variables, then the values decreased in the second factor till the Initial Eigenvalues reached 3175 with variance of 26,459 and cumulative percent $71,969 \%$ and the lowest value of Initial Eigenvalues was recorded in the third factor, which ranks last, as this factor was stopped with Initial Eigenvalues amounted 1392 and variance ration amounted 11,602 and cumulative percent amounted 83,571. Thus three important factors specific to the frequency of sandstorms in the Kingdom of Saudi Arabia have been identified.

4) Determining the correlation of months with the derived factors, by extracting factor loading as indicated in Table 5. They are values indicating the amount of correlations between the variables on the one hand and the factors that have been identified on the other hand. The factor loading was determined by relying on the Varimax Rotation method, which is one of the most important methods by which the values of loading can be rotated, because it aims to maximize the variance set for the squares of the factor loading, so that each variable has one high loading on one of the factors, that is, to be Close to one integer at the same time, it is low on the other factor, by whether it is zero or close to zero, and the higher the correlation relationship between the variable and the factor is high, the more this indicates the correlation and dependence of months on the factor, and accordingly the association of months was determined with the derived factors, as follows:

Table 4. Contributions of derived factors and the variations' ratios for each factor.

\begin{tabular}{cccc}
\hline Component & Initial Eigenvalues & \% of Variance & Cumulative $\%$ \\
\hline 1 & 5.461 & 45.510 & 45.510 \\
2 & 3.175 & 26.459 & 71.969 \\
3 & 1.392 & 11.602 & 83.571 \\
4 & 0.706 & 5.886 & 89.457 \\
5 & 0.449 & 3.741 & 93.198 \\
6 & 0.335 & 2.791 & 95.989 \\
7 & 0.198 & 1.650 & 97.639 \\
8 & 0.101 & 0.845 & 98.484 \\
9 & 0.078 & 0.650 & 99.134 \\
10 & 0.048 & 0.397 & 99.532 \\
11 & 0.034 & 0.279 & 99.811 \\
12 & 0.023 & 0.189 & 100.000 \\
\hline
\end{tabular}

Source: Factor analysis outcomes. 


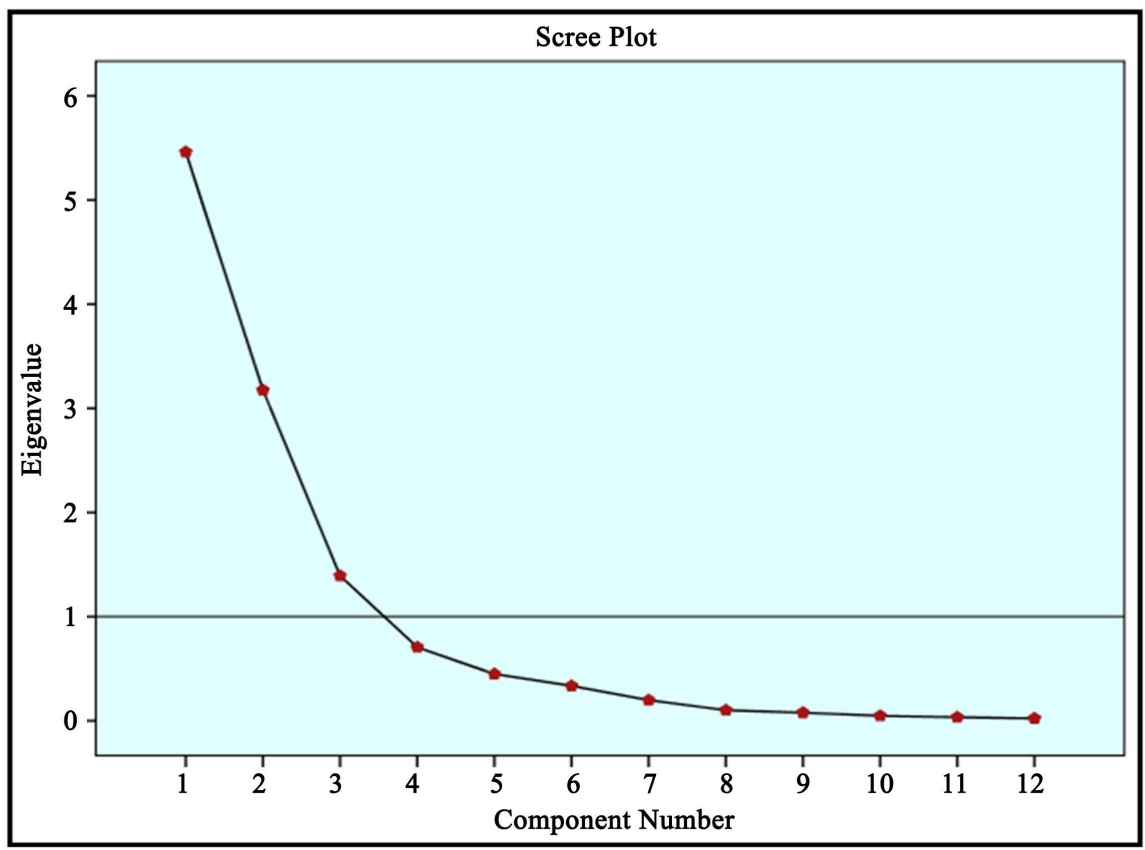

Figure 2. Contributions of derived factors (Scree Plot). Source: Factor analysis outcomes.

Table 5. The values of the derived variables and their correlation with factors.

\begin{tabular}{cccc}
\hline & \multicolumn{3}{c}{ Component Matrix $^{\mathrm{a}}$} \\
\hline & 1 & Component & \\
\cline { 2 - 4 } & 0.670 & 2 & 3 \\
\hline January & 0.847 & -0.380 & -0.360 \\
February & 0.845 & -0.406 & -0.150 \\
March & 0.894 & -0.392 & -0.157 \\
April & 0.849 & -0.215 & -0.039 \\
May & 0.735 & -0.083 & 0.177 \\
June & 0.341 & 0.382 & -0.426 \\
July & 0.328 & 0.687 & -0.485 \\
August & 0.402 & 0.919 & -0.077 \\
September & 0.504 & 0.805 & 0.258 \\
October & 0.810 & 0.510 & 0.630 \\
November & 0.474 & 0.058 & 0.322 \\
December & Extraction Method: Principal Component Analysis. & 5.439 \\
& & -0.534 &
\end{tabular}

Source: Factor analysis outcomes. a. 3 components extracted.

\subsection{First Factor}

This factor is considered one of the strongest factors, due to the high value of the roots inherent in it, as previously mentioned, which reached 5461. It is also characterized by the high values of the interpreted variance, which amounted to 0.5 
which reached 7 variables. April came in the first place as the most important months in relation to the factor with loading percent equal to 0.894 followed by May, February, March and November, with a loading degree equal to 0.894, $0.847,0.845,0.810$ respectively, then June with a value of 0.735 . An finally January with loading percent equals 0.675 .

It is clear that the previous months came as the strongest variables related to the first factor, which indicates frequency of sandstorms in Kingdom of Saudi Arabia and since the strongest values of loading came for the months of the spring season, this factor was called the spring factor.

\subsection{Second Factor}

In terms of importance, this factor comes in the second place as it included Initial Eigenvalues amounted 3175, the variance value amounted $26,459 \%$ of the variance ratio explained in the original variables, and this factor has been associated with a number of positive variables whose correlations exceed 0.5. Table 5 showed that the number of months associated with this factor has reached three. August comes in the 1st place with loading amount equal to 0.919 followed by September with loading amount 0.805 and followed by July with loading amount 0.687 .

According to the correlations between the three months and the second factor, it can be said that the second period of sandstorm recurrence is from July to September, and where the period includes two months of the summer months, which is July and August. This factor was called the "Summer season" factor.

\subsection{Third Factor}

In terms of importance, this factor comes in the second place as it included Initial Eigenvalues amounted (1392), the variance value amounted $11,602 \%$ of the variance ratio explained in the original variables. The percentage of the contribution of this factor in explaining the information contained in the original variables does not mean that it is not important, but rather has a characteristic as a separate axis from the rest of the axes, to clarify the frequency of sandstorms in the rest of the months of the year, as this factor is associated with one positive variable according to its correlations of more than $50 \%$, as shown in Table 5, and represented in October with loading degree of 0.630 . This factor was called the "Autumn season" factor.

\section{Spatial Variation of Sandstorms in Saudi Arabia}

The variance of sandstorms distribution in the Kingdom of Saudi Arabia in the study stations of the number 27 stations was analyzed, depending on the results of the spatial variance analysis of the frequency of sandstorms, through the "Factor Scores", which represents the degree of importance and impact of the weather monitoring stations on the factor and is related to the mean of storms In sandy areas, and these values fluctuate between positive and negative values, as 
the higher the positive values of the factor degrees. This means the more positive values of the factor degrees, the more this indicates the importance of the meteorological stations in the world. Also, when the values are negative, this indicates the weakness of its importance, and the following is an analysis of the spatial variation of the frequency of sandstorms according to the degrees of each of the factors that were previously determined, as shown in Table 6 and Figure 3, as follows:

\subsection{Spatial Variance According to First Factor (Spring)}

This factor was called "Spring Season Factor" for the frequency of sandstorms. The factor degrees associated with it came between positive and negative degrees, as shown in previous Table 5. Accordingly, kingdom stations were divided according to the degrees of this factor into categories, as shown in Table 6 and Figure 3, as follows:

Table 6. Factor scores of sandstorms in Saudi Arabia.

\begin{tabular}{|c|c|c|c|c|}
\hline Component & Station & factor 1 & factor 2 & factor 3 \\
\hline 1 & Turaif & -0.19776 & -0.67483 & 1.47456 \\
\hline 2 & Arar & 0.29864 & -0.69154 & 1.08211 \\
\hline 3 & Guriat & -0.32024 & -0.44294 & 672900 \\
\hline 4 & Al-Jouf & 1.04284 & -0.46959 & 1.19683 \\
\hline 5 & Rafha & 0.78120 & -0.40889 & 1.17343 \\
\hline 6 & Gaisumah & 0.70964 & -0.19215 & -0.12649 \\
\hline 7 & Tabuk & -0.72983 & 0.06914 & -0.02855 \\
\hline 8 & Hafr Elbatten & 1.83282 & -0.52918 & 1.11718 \\
\hline 9 & Hail & -0.20048 & -0.62747 & 0.18322 \\
\hline 10 & Wejh & -1.13175 & -0.09956 & -0.09569 \\
\hline 11 & Qassim & 0.04855 & -0.56169 & 0.77230 \\
\hline 12 & Dhahran & -0.52669 & -0.19399 & -0.12866 \\
\hline 13 & Al-Ahsa & 3.00265 & -1.41191 & -2.41354 \\
\hline 14 & Madinah & -0.79832 & -0.15497 & -0.05360 \\
\hline 15 & Riyadh & -0.49817 & -0.23898 & -0.13908 \\
\hline 16 & Yenbo & 0.49258 & 1.65034 & -2.02936 \\
\hline 17 & Jeddah & -0.46895 & -0.32713 & 0.17782 \\
\hline 18 & Makkah & -1.21892 & 0.05335 & -0.31828 \\
\hline 19 & Taif & -0.84860 & 0.18116 & 0.09015 \\
\hline 20 & Al-Baha & -0.87208 & 0.02965 & -0.62086 \\
\hline 21 & Wadi Dawasir & 0.64903 & -0.33884 & -0.28312 \\
\hline 22 & Bisha & 0.17250 & -0.07181 & 0.80229 \\
\hline 23 & Abha & -1.07665 & 0.09253 & -0.58353 \\
\hline 24 & Khamis Mushait & -1.16099 & 0.19607 & -0.48488 \\
\hline 25 & Najran & -0.24240 & 0.43448 & -1.10070 \\
\hline 26 & Sharorah & -0.05209 & 0.50348 & -1.65350 \\
\hline 27 & Jazan & 1.31347 & 4.22527 & 1.31707 \\
\hline
\end{tabular}

Source: Factor analysis outcomes. 


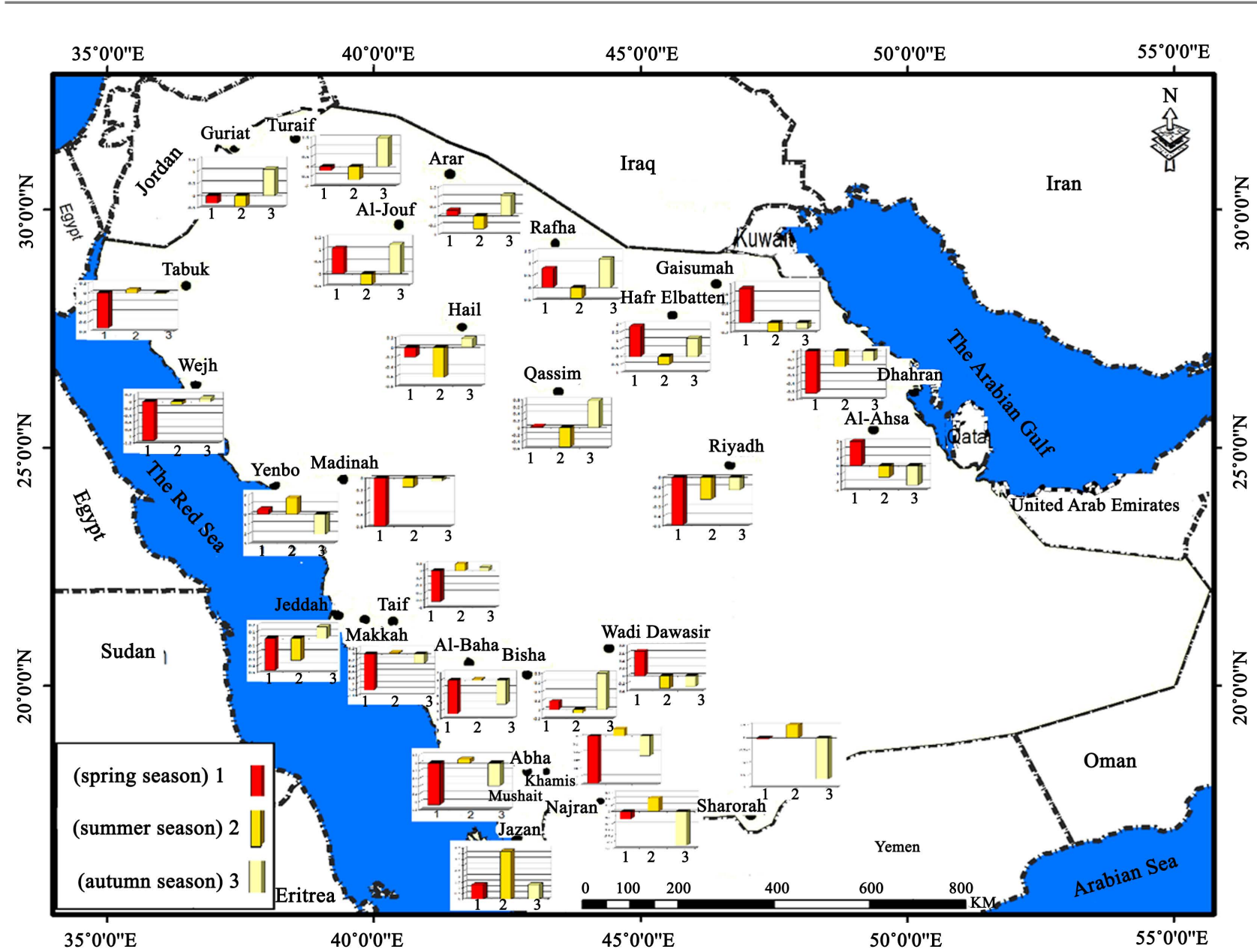

Figure 3. Distribution of sandstorms in Saudi Arabia. Source: based on the data of Table 6.

- The stations that included positive values are higher than integer (1), and included four stations that occupied the first places among the Kingdom's stations in sandstorms, especially in the spring seasons. Al-Ahsa ranked first with a very high value of 3.00 followed by Hafr Elbatten with positive value of 1.832 degrees, then Jazan Station and Al-Jouf station, With an amount exceeding integer (1) due to the effect of the passing air depressions in the region accompanied by the front cold weather, which lead to attracting warm air currents with the advancement of Sudan's seasonal depression [15], which affects the west and southwest of the Kingdom, especially in the spring season through the blowing of Hot and dry winds carry huge amounts of dirt and dust to the upper atmosphere.

Stations including positive values less than integer (1) represent (7) stations namely Rafha station and Gaisumah station with a value exceeding 0.700 followed by Wadi Dawasir station, with value equal to 0.649 followed by both Yanbu Station), Arar station (0.298), Bisha station (0.172), Qassim station with values ranging between 0.492 and 0.048 degrees.

- Stations including negative values less than (zero). These stations are among the Kingdom's lowest stations subject to Sand storms in spring including 
Makkah station, Khamis Mushait station, Abha station, Wejh with an amount exceeding -1.0 followed by Al-Baha, Taif, Madinah, Tabuk, Dhahran, Riyadh and Jeddah stations with amount ranging between -0.872 and 0.468. The highest storm stations in this category are Guriat, Turaif, Hail, Najran, and Sharorah with an amount rang in between, -0.320 and -0.052 .

\subsection{Spatial Variance of Sandstorm Reoccurrence According to Factor 2 (Summer)}

In terms of importance Second factor came (which was called "summer factor") for the frequency of sandstorms, ranked second. The degrees of the factor, as shown in Table 6 and Figure 3, came between positive and negative values, and in light of these values, the kingdom's stations can be divided according to factor into the following categories:

- Stations including positive values higher than integer (1): Jazan Station ranked 1st among the regions of the Kingdom in the frequency of sand storms within this category according to the summer season factor, with a very high value of (4220) due to the fact that Jazan region is exposed to a state of air instability, during summer, due to high temperature during the day, which leads to the presence of ascending air currents that lift dust with it, in addition to the predominance of the southwest winds under the influence of India's seasonal depression, which raises large quantities of dust and sand, in addition to the northwest winds that raise dust from the local environment in the west of the region, where coastal sand dunes gatherings that extend longitudinally along the coast of the Red Sea [2]. Yenbo station ranked 2nd in this category with a value of (1650 degrees), due to the dominance of the northwestern winds that are active due to meteorological phenomenon above the Mediterranean Sea which results in stirring dust and dirt in the west of the Kingdom.

- Stations with positive values less than integer (1): Sharorah station ranked 1st with a value of (0.503), followed by Najran station with an amount of (0.434) followed by the rest stations Tabuk, Taif, Khamis Mushait, Makkah and Abha with a value equal to (0.029). This is due to the confluence of the average eastern depression with the depressions coming from North Africa, such as the seasonal depression of Sudan on the Sarawat Mountains, which results in the occurrence of dust and sand storms in the southwestern regions of the Kingdom, as the surface is hot, which leads to A state of instability in the lower parts of the air, which helps the activity of the rising currents that carry dust and dust to the upper atmosphere.

- Stations with negative values less than zero, amounted 17 stations: Al-Ahsa station ranked 1st in terms of few sandstorms according to the summer season factor, with the degrees of this factor reaching (-1411) followed by Arar, Turaif, Hail, Guriat, Al-Jouf, Rafha, Dhahran, Hafr Elbatten, Gaisumah, Wejh, Qassim, Madinah, Riyadh, Jeddah, Wadi Dawasir and Bisha stations with an amount of $(-0.071)$. This means that most of the northern and cen- 
tral regions of the Kingdom of Saudi Arabia are characterized by the low frequency of sandstorms during summer in general, due to their distance from the influence of the depressions.

\subsection{Spatial Variance According to Factor 3 (Autumn)}

- In terms of importance, Factor (3) ranked in the last place. This factor was called "Autumn factor". Despite the low contribution of this factor, it highlights certain periods in which sandstorms are concentrated, and the grades of the factor, as shown in Table 6 and Figure 3, came between positive and negative values, and in light of those values, the Kingdom's stations can be divided according to the worker's degrees into the following categories:

- Stations including positive values higher than integer (1) including six stations, Turaif stations came at the forefront, where sandstorms are concentrated according to the degrees of the third factor in Autumn with an amount of (1474), as the northwestern part of the Kingdom is affected in Autumn with atmospheric instability as a result of hot waves that raise dust and sand. Its influence extends along the western coasts of the Kingdom due to local factors, resulting from the variation in the values of atmospheric pressure, followed by the Jazan Station located on the southwestern coast of the Kingdom, with a value of (1317 degrees), and most stations located within this Category in the north of the Kingdom represented in Al-Jouf, Rafha, Hafr Elbatten and Arar stations with value exceeding 1 integer.

- Stations containing positive values less than integer (1) including six stations, Bisha station ranked 1st with a value of 0.802 degrees, followed by Qassim station (0.772 degrees) the Guriat (0.672), Hail and Jeddah with $(0.183$ and $0.177)$. Taif station ranked in the last place with an amount equal to (0.090). These areas are subject to frequent sandstorms of moderate degree as atmospheric instability begins to control these areas.

- Stations with negative values less than zero including 15 stations: Al-Ahsa, Yenbo, Sharorah, and Najran ranked 1st which are characterized by the low frequency of sandstorms in Autumn with values ranging between (-2413) and $(-1100)$ followed by Al-Baha, Abha, Khamis Mushait, Makkah, Wadi Dawasir, Riyadh, Dhahran, and Gaisumah with values ranging between $(-0.620$ and -0.126$)$. Finally, Wejh, Madinah, and Tabuk with values of $(-0.095,-0.053,-0.028)$ respectively. This is due to weak atmospheric stability in these areas during summer.

\section{Conclusions}

The study literature concerned with the classification of sandstorms and their geographical distribution in Saudi Arabia. Among the most prominent findings of the study is that Spring represents the first period for the recurrence of sandstorms, as April and May ranked 1st as the most important months in relation to the frequency of sandstorms in the Kingdom of Saudi Arabia. While the 
second recurrence period of sandstorms is from July to September, associated with a strong positive relationship, as indicated by the results of the second factor. The study also highlighted that October represents the third period for the frequency of sandstorms in the Kingdom of Saudi Arabia, according to the results of the third factor. According to the results of the third factor, sandstorm activity is also reduced in the Kingdom during the winter. One of the most important results of the spatial distribution of the study is that the meteorological stations vary in the frequency of sandstorms, with Al-Ahsa, Hafr Elbatten, Jazan and $\mathrm{Al}$-Jouf stations ranked first in terms of frequency of sandstorms during Spring, while Jazan and Yenbo stations ranked first in summer. As for the northern stations of the Kingdom, such as Tarif, Al-Jazaf, Rafa and Arar, they ranked first during the autumn season. While areas located in mountainous heights, such as the Asir region, are among the least exposed to frequent sandstorms in the Kingdom of Saudi Arabia in most of the year. Hence, the following recommendations can be made to address the impact of sandstorms on the Kingdom:

- Using technologies on weather phenomena locally and regionally, by creating a database to final out the damage resulting from those phenomena.

- Preparing accurate maps that illustrate the seasonality of dust storms of their geographical distribution.

- Work to set up indicative panels on the dangers of sandstorm along the highways.

- Expanding green areas around cities and villages, due to their importance in reducing the impact of sandstorms.

- Limiting the spread of sports activities on sand dunes, which leads to loosening of dust and sand.

- Population training of the most important ways that reduce the impact of sandstorms, such as avoiding intrusions and overgrazing. In addition to using national celebrations and events as times for spreading environmental awareness.

- Setting strategies issued by decision-makers in order to cope with the dangers resulting from storms, when developing environmental resources development plans, such as increasing the number of weather monitoring stations in various regions of the Kingdom and providing them with the latest weather monitoring devices.

\section{Acknowledgements}

The author thanks the General Authority of Meteorology, and Environment Protection in Saudi Ariba for all available data which help me in research.

\section{Conflicts of Interest}

The author declares no conflicts of interest regarding the publication of this paper. 


\section{References}

[1] Qurba, J.M. (1982) Joint Work and Its Results for the Low Eastern Mediterranean and the Sudan Depression on the Southwest of the Kingdom of Saudi Arabia. The 5th Conference on Biological Aspects, Riyadh, 1-3 March 1982, 1-86.

[2] General Authority for Statistics, Department of Statistics (2019) Statistical Yearbook. Press of the Department of Statistics and Information, Riyadh.

[3] Al-Qalawi, S. (1983) Climate and Its Impact on the Environment in the Western Desert of Egypt. Unpublished PhD Thesis, Ain Shams University, Egypt.

[4] Safar, M.E. (1985) Dust in Kuwait during Summer. Gulf and Arabian Peninsula Studies Journal, 30, 55-74.

[5] Al-kulib, A. (1990) The Climate of the Arabian Gulf. National Library, Abu Dhabi, UAE.

[6] Taher, A. (1996) Sand and Dust Storms and Their Impact on the Soils of Agricultural Fields in Al-Ahsa Oasis in the Kingdom of Saudi Arabia. Saudi Geographical Society, King Saud University, Riyadh.

[7] Salim, M.S. (2000) The Natural Environment, Its Characteristics and Human Interaction with It. Dar Alfikr Alaraby, Cairo.

[8] Tayyib, N.T. and Jarar, B.M. (2002) Dust Pollution. Al-Yamamah Press Foundation, Riyadh.

[9] Salem, T.Z. (2004) Sand and Dust Storms and Their Impact on Agriculture in Jizan Region, Saudi Arabia. Arab Geographical Journal, 44, 1-36.

[10] Arishi, A.A.M. (2008) Storms and Their Impact on Development in the Jazan Region: A Study in Applied Climate. Unpublished PhD Thesis, Faculty of Education, King Khalid University, Abha.

[11] Al-Mutairi, M. (2015) Dust Storms in the Regions of Riyadh and Qassim, and the Climatic Factors Affecting Them. Journal of Arabic and Human Sciences, 8, 1021-1096.

[12] Abd Al-Halim, M.A. (2015) Sandstorms and Their Impact on Some Agricultural Crops in the Western Part of the Republic of Northern Sudan. Journal of the Center for Geographical and Cartographic Research, 22, 69-134.

[13] Habib (2016) Monitoring and Analyzing Violent Sand Storms in the Kingdom of Saudi Arabia Using Satellite Images. Geographical Publications Magazine, 5, 89-105.

[14] Al-Loula (2017) Sandstorms and Their Impact on Agricultural Crops in the Central Region of the Kingdom of Saudi Arabia, from 2001 till 2016. Arab Journal of Social Sciences, 12, 49-97.

[15] Presidency of Meteorology and Environmental Protection (2019) Sand and Dust Storms, Quarterly Forecast (March to May). 11th Edition, Scientific Information and Documentation Center, Climate Management. 


\section{Appendix}

Table A1. Average frequency of monthly sandstorms in the Kingdom of Saudi Arabia, during the period from 1989 to 2019.

\begin{tabular}{|c|c|c|c|c|c|c|c|c|c|c|c|c|}
\hline Station & 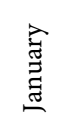 & 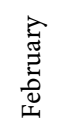 & 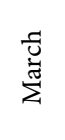 & 竞 & $\stackrel{\widehat{\Xi}}{\Sigma}$ & $\underset{\Xi}{\Xi}$ & $\triangleq$ & 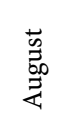 & 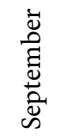 & $\begin{array}{l}\grave{D} \\
\stackrel{0}{0} \\
\stackrel{0}{0}\end{array}$ & $\begin{array}{l}\overline{0} \\
\text { हี } \\
0 \\
0 \\
\text { Z }\end{array}$ & 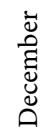 \\
\hline Turaif & 0.03 & 0.26 & 0.33 & 0.50 & 0.63 & 0.16 & 0.03 & 0.0 & 0.03 & 0.26 & 0.16 & 0.50 \\
\hline Arar & 0.20 & 0.40 & 0.66 & 1.26 & 0.10 & 0.03 & 0.03 & 0.0 & 0.10 & 0.26 & 0.30 & 0.30 \\
\hline Guriat & 0.16 & 0.23 & 0.53 & 0.40 & 0.86 & 0.03 & 0.0 & 0.06 & 0.06 & 0.30 & 0.03 & 0.23 \\
\hline Al-Jouf & 0.36 & 0.90 & 1.26 & 1.33 & 0.96 & 0.33 & 0.0 & 0.30 & 0.03 & 0.70 & 0.46 & 0.23 \\
\hline Rafha & 0.16 & 0.76 & 1.10 & 1.86 & 1.66 & 0.23 & 0.03 & 0.10 & 0.23 & 0.53 & 0.20 & 0.20 \\
\hline Gaisumah & 0.10 & 0.70 & 1.13 & 1.86 & 1.83 & 0.50 & 0.43 & 0.06 & 0.13 & 0.20 & 0.20 & 0.06 \\
\hline Tabuk & 0.0 & 0.16 & 0.30 & 0.56 & 0.40 & 0.0 & 0.06 & 0.13 & 0.10 & 0.20 & 0.03 & 0.0 \\
\hline Hafr Elbatten & 0.16 & 1.7 & 1.86 & 2.76 & 1.80 & 0.56 & 0.26 & 0.30 & 0.26 & 0.20 & 0.53 & 0.30 \\
\hline Hail & 0.30 & 0.30 & 0.50 & 0.90 & 0.76 & 0.06 & 0.03 & 0.06 & 0.06 & 0.20 & 0.0 & 0.23 \\
\hline Wejh & 0.0 & 0.0 & 0.0 & 0.0 & 0.2 & 0.0 & 0.06 & 0.0 & 0.0 & 0.03 & 0.0 & 0.06 \\
\hline Qassim & 0.10 & 0.40 & 0.83 & 0.90 & 0.0 & 0.10 & 0.06 & 0.06 & 0.10 & 0.23 & 0.06 & 0.26 \\
\hline Dhahran & 0.16 & 0.10 & 0.70 & 0.30 & 0.0 & 0.10 & 0.06 & 0.03 & 0.06 & 0.20 & 0.06 & 0.03 \\
\hline Al-Ahsa & 0.76 & 2.33 & 2.10 & 2.26 & 0.0 & 1.66 & 0.40 & 0.30 & 0.30 & 0.10 & 0.40 & 0.30 \\
\hline Madinah & 0.13 & 0.06 & 0.06 & 0.33 & 0.0 & 0.0 & 0.16 & 0.10 & 0.0 & 0.13 & 0.0 & 0.13 \\
\hline Riyadh & 0.10 & 0.30 & 0.13 & 0.83 & 0.0 & 0.06 & 0.23 & 0.06 & 0.06 & 0.0 & 0.06 & 0.13 \\
\hline Yenbo & 0.10 & 0.0 & 0.43 & 1.20 & 0.0 & 1.36 & 1.16 & 1.10 & 0.16 & 0.06 & 0.16 & 0.0 \\
\hline Jeddah & 0.20 & 0.10 & 0.43 & 0.53 & 0.0 & 0.10 & 0.0 & 0.13 & 0.06 & 0.13 & 0.20 & 0.16 \\
\hline Makkah & 0.0 & 0.03 & 0.06 & 0.0 & 0.0 & 0.0 & 0.0 & 0.10 & 0.06 & 0.0 & 0.0 & 0.0 \\
\hline Taif & 0.06 & 0.0 & 0.06 & 0.06 & 0.0 & 0.06 & 0.06 & 0.16 & 0.16 & 0.13 & 0.13 & 0.06 \\
\hline Al-Baha & 0.13 & 0.0 & 0.36 & 0.06 & 0.0 & 0.06 & 0.10 & 0.26 & 0.03 & 0.0 & 0.03 & 0.0 \\
\hline Wadi Dawasir & 0.16 & 0.40 & 1.10 & 1.66 & 0.0 & 0.10 & 0.66 & 0.30 & 0.10 & 0.06 & 0.10 & 0.20 \\
\hline Bisha & 0.16 & 0.20 & 0.36 & 0.96 & 0.0 & 0.06 & 0.30 & 0.43 & 0.03 & 0.23 & 0.40 & 0.26 \\
\hline Abha & 0.06 & 0.0 & 0.06 & 0.03 & 0.0 & 0.13 & 0.10 & 0.16 & 0.0 & 0.0 & 0.03 & 0.0 \\
\hline Khamis Mushait & 0.0 & 0.03 & 0.03 & 0.0 & 0.0 & 0.10 & 0.10 & 0.16 & 0.06 & 0.0 & 0.0 & 0.0 \\
\hline Najran & 0.20 & 0.0 & 0.43 & 0.76 & 0.0 & 0.16 & 0.73 & 0.53 & 0.06 & 0.10 & 0.03 & 0.06 \\
\hline Sharorah & 0.20 & 0.0 & 1.0 & 0.83 & 0.0 & 0.46 & 0.93 & 0.46 & 0.06 & 0.06 & 0.0 & 0.03 \\
\hline Jazan & 0.0 & 0.0 & 0.0 & 0.06 & 0.0 & 1.06 & 1.03 & 1.90 & 1.63 & 1.20 & 0.36 & 00.0 \\
\hline
\end{tabular}

Source: The presidency of meteorology and environmental protection, 2020. 